\title{
MODELLING DECISION MAKING IN THE MANAGEMENT OF NATIONAL PARKS
}

\author{
Diego Díaz-Martín \\ Departamento de Estudios Ambientales \\ Universidad Metropolitana (Caracas, Venezuela) \\ E-mail: ddiaz@unimet.edu.ve \\ Tomás Gómez-Navarro \\ Departamento de Proyectos de Ingeniería \\ Universitat Politècnica de València (Valencia, España) \\ E-mail: tgomez@dpi.upv.es \\ Mónica García Melón \\ Departamento de Proyectos de Ingeniería \\ Universitat Politècnica de València (Valencia, España) \\ E-mail: mgarciam@dpi.upv.es
}

\begin{abstract}
A procedure for determining the influential factors in NP management and supporting participatory decision making is proposed. The procedure was applied to the Waraira Repano national park (WRNP) in Venezuela. Key aspects found for the effective management of WRNP showed to be Driving forces like "Human population growth" or "Patterns of use of natural resources"; Pressures like "Forest fires" and "Illegal human settlements"; States like "Biodiversity composition and abundance" and "Ecosystem and landscape integrity"; Impacts like "Natural resources depletion" or "Altered connectivity"; and Responses like "Stakeholders" participation" or "Environmental surveillance". Finally, key indicators have been proposed to monitor the evolution of these influential factors.

Also, the findings confirm that stakeholders hold different interests, approaches to sustainability and sensitivities. After ANP all stakeholders understand better their interests and the others'. Thus, an improved participation is obtained and a consensus, or at least general agreements, is more likely. Also a better commitment to the overall objective is achieved as the decision model facilitates improving the alternatives design in order to lessen the possible burdens for specific stakeholders or the environment.
\end{abstract}

Keywords: DPSIR, National Parks, Waraira Repano, Analytic Network Process (ANP), Natural Parks management. 
Modelling decision making in the management of national parks: Díaz-Martin et al. , International Symposium of the Analytic Hierarchy Process 2014, Washington D.C.,

U.S.A.

\section{Introduction}

Despite the importance of National Parks, the management of many of these areas face serious difficulties determined by a variety of shortcomings, one of the most important being the incomplete monitoring system and the lack of collaboration of all involved stakeholders.

Regarding the first flaw, this research examines the influential factors for successful management of a national park from the Driving forces-Pressures-State-Impact-Response approach (DPSIR). The DPSIR approach allows, on the one hand arranging a complete set of influential factors to consider in the management system. On the other hand DPSIR clarifies the cause-effect relationships among influential factors towards a more effective and efficient management. Finally, DPSIR approach provides a common management language for a better integration of the management system in the other systems of the public administration.

Regarding the lack of effective cooperation among stakeholders, the Analytical Network Process (ANP) is used for modeling the decision problem and helping stakeholders to participate assessing the sustainability of the solution alternatives. In the presented methodology, a panel of experts in natural areas management, and specifically in the WRNP, was arranged to determine the decision model i.e. the network of criteria and alternatives structured into clusters. Five clusters were set according to the DPSIR structure, where the Responses were the alternatives. The obtained model showed not only the decision problem as it is, but the relationships among stakeholders when discussing which action to take.

\section{Literature Review}

According to several authors, national parks suffer from threats that compromise the performance of their objectives (Fancy et al, 2009; Tallis et al, 2010) . According to ParksWatch (2004), the Waraira Repano National Park can be classified as vulnerable due to its location and accessibility. The main threats identified by Diaz- Martin et al. (2008) and ParksWatch (2004) are:

- Forest fires ravaging thousands of acres of park per year, either by human or natural conditions

- Changes in land use, due to expansion of the agricultural frontier,

-Edge effects due to the expansion of the protected area surrounding populations,

-Invasions of exotic species in the protected area,

- Centralization of resources deposited by the ticket office park, not re- invested in the same protected area,

-Project proposals to modify the boundaries of the park for housing construction, -Ilegal hunting and

-Poor waste and solid waste management.

The participation of key stakeholders in the management of protected areas, has been recognized by various stakeholders as one of the solutions to ensure the conservation objectives of the area (Taring, 1992. Buta et al, 2014). Co-management, ie, sharing the 
Modelling decision making in the management of national parks: Díaz-Martin et al. , International Symposium of the Analytic Hierarchy Process 2014, Washington D.C., U.S.A.

responsibility of management is an internationally growing trend, which takes different forms depending on the country and its administrative structure (Brown and Harris, 2005. Daim et al, 2012).

The ultimate goal is to generate participatory management mechanisms to meet the challenges of conservation, incorporating local actors to support the decision-making processes related to management. These include the achievement of adequate resources for management, access to key information and the adoption of commitments by the actors themselves, to contribute to management programs.

The Driving forces-Pressures-State-Impact-Response approach (DPSIR) has been broadly used in the environmental field, particularly in items related to sustainability (de Felipe \& Sureda, 2009; Ness et al., 2010; Sotelo et al., 2011; Tscherning et al., 2012).

FPEIR has also been applied in several studies which highlight its utility in the analysis of biodiversity (Maxim et al, 2009;. Omann et al, 2009), the evaluation of the ecosystem (Atkins et al, 2011.) and agriculture and fisheries (Mangi et al., 2007), among others.

Several applications related to environmental objectives using ANP (Saaty, 2005) have been developed. These include a research related to the evaluation of strategies for sustainable forest management, environmental assessment of the risk level of long-term deterioration of different ecosystems in the United States (Tran et al, 2004) the decision on the license of a nuclear plant in Finland (Hämäläinen and Seppäläinen, 1986); sustainability of tourism in the National Park Los Roques in Venezuela (García-Melon et at, 2012.) and also a research for the National Park Simen Mountains in Ethiopia

\section{Research Design/Methodology}

The figure below presents an overview of the methodology, which analyzes the DPSIR (Drivers, Pressures, States, Impacts and Responses) and the Analytic Network Process

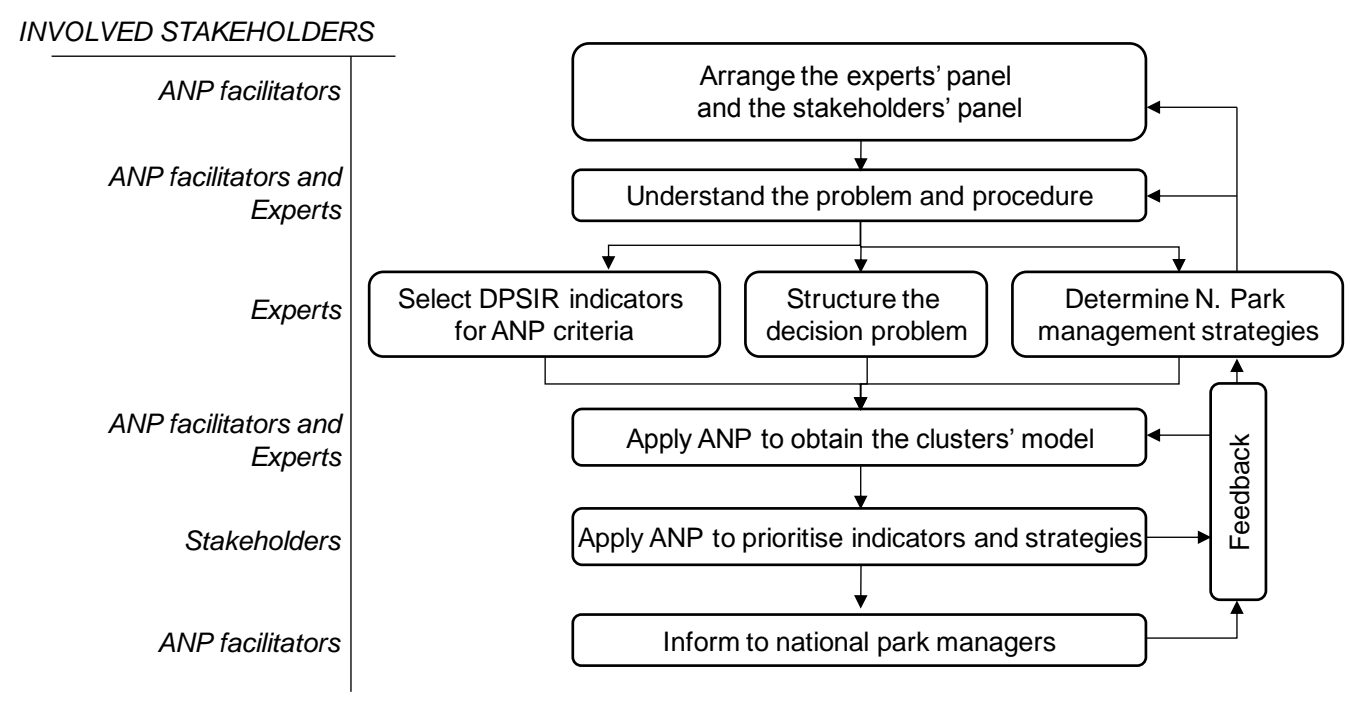

Figure 1: Methodology proposed

International Symposium of 3

Washington, D. C. the Analytic Hierarchy June 29 - July 2, 2014

Process 
Modelling decision making in the management of national parks: Díaz-Martin et al. , International Symposium of the Analytic Hierarchy Process 2014, Washington D.C., U.S.A.

Through the DPSIR methodology the most important factors for managing the park are selected and the cause-effect relationships are established which are subsequently evaluated in the ANP.

In ANP the most influential factors in the participatory management of the national park are determined and after that, recommendations are made to promote a management focused towards sustainability.

A total amount of 6 expert attended the focus group. All of them have a broad experience in the subject under study and know the protected area, which is essential for achieving the objectives at this stage of the investigation. The experts were:

-Expert 1 : Representing Inparques actors: Mr. Jairo Vargas, Technical Coordinator of the National Park Waraira Repano, Inparques

- Expert 2 : On behalf of the actors in the Ministry of Environment : Armando Rangel, Director of Plans MinAmb , Capital Region, former director of Inparques

- Expert 3 : On behalf of the scientific and university sector : Teacher and researcher Edgar Yerena, Universidad Simón Bolívar, former Director of Management of National Parks Inparques

- Expert 4: Representing NGOs : Ing Yazenia Frontado, Project Director of Vitalis, who is also Technical Coordinator of the Avila Project at the Metropolitan University .

- Expert 5 : On behalf of the residents and visitors : Mr. Alberto Blanco, tour operator in Waraira Repano national park, conservation magazine Editor Rio Verde .

- Expert 6 : Facilitator and Researcher, author of this work, Head of Department of Environmental Studies at Metropolitan University (Caracas)

\section{Data/Model Analysis}

The following figure summarizes the proposed factors, grouped into five clusters, corresponding to Drivers, Pressures, Impacts, Response and States. 
Modelling decision making in the management of national parks: Díaz-Martin et al. , International Symposium of the Analytic Hierarchy Process 2014, Washington D.C., U.S.A.

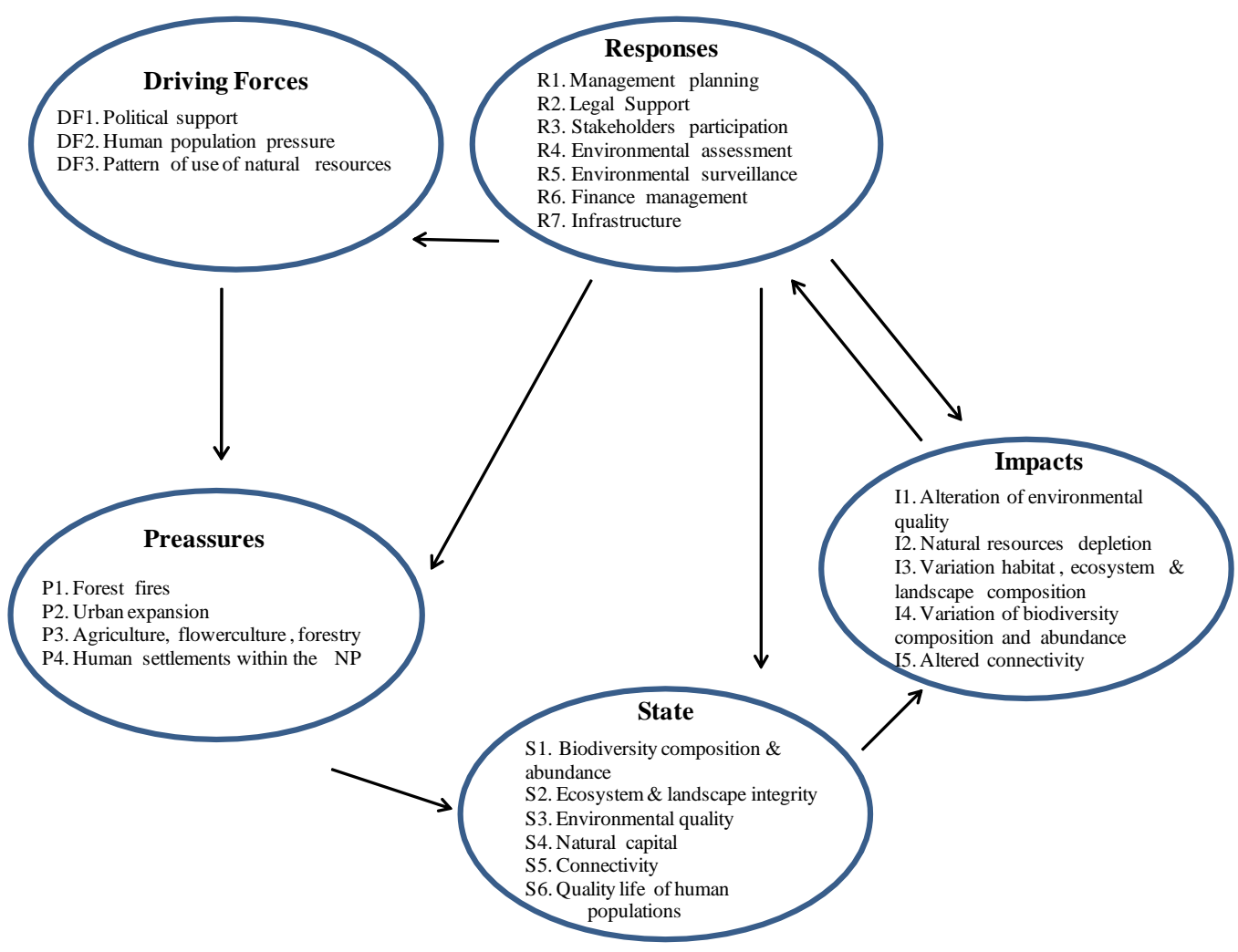

Figure 2: Main influential factors in PN Waraira Repano management

In the following figure the ANP network model is presented: 
Modelling decision making in the management of national parks: Díaz-Martin et al. , International Symposium of the Analytic Hierarchy Process 2014, Washington D.C., U.S.A.

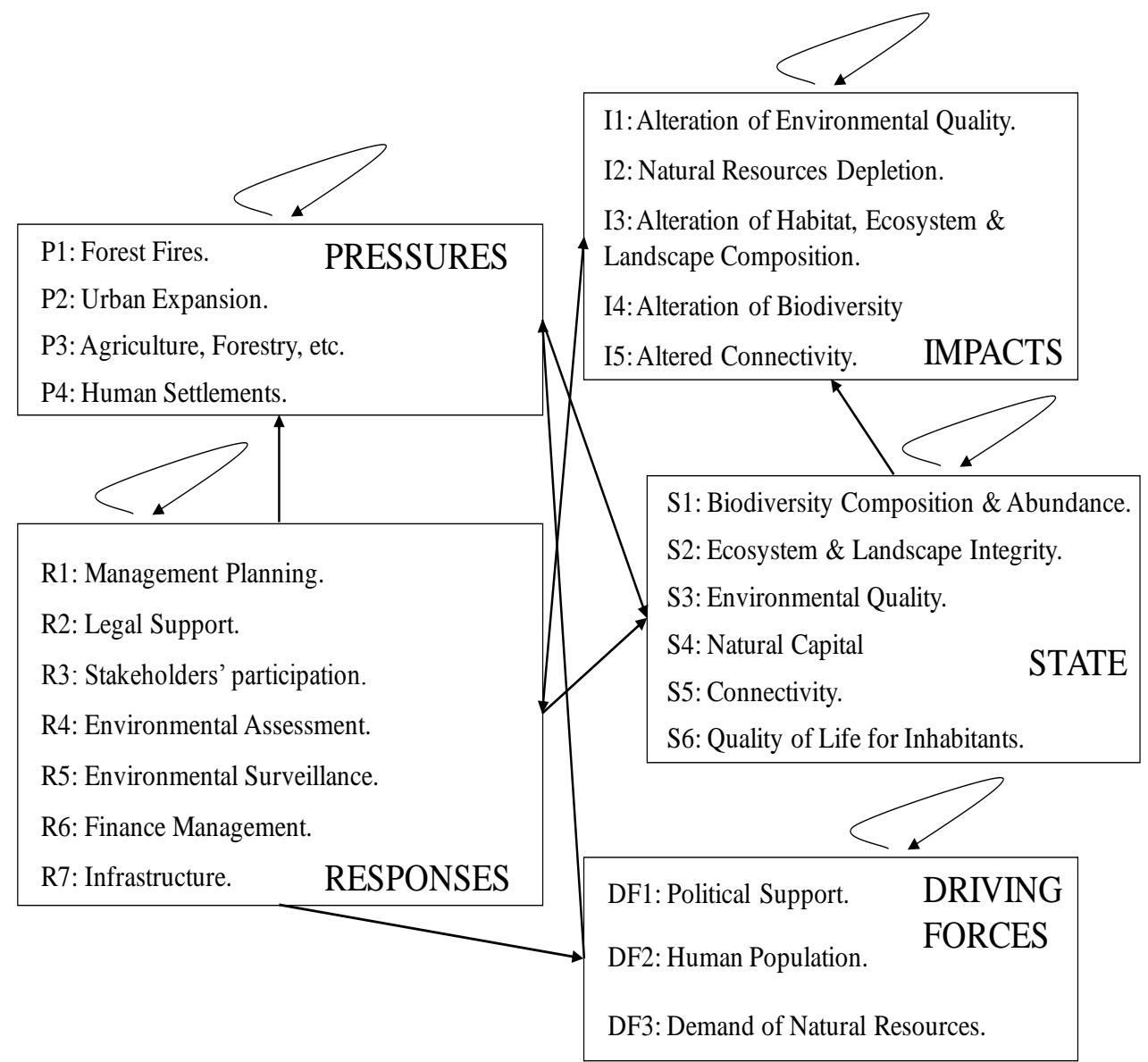

Figure 3: Network model for the decision making problem

The following table also presents the results of the network model

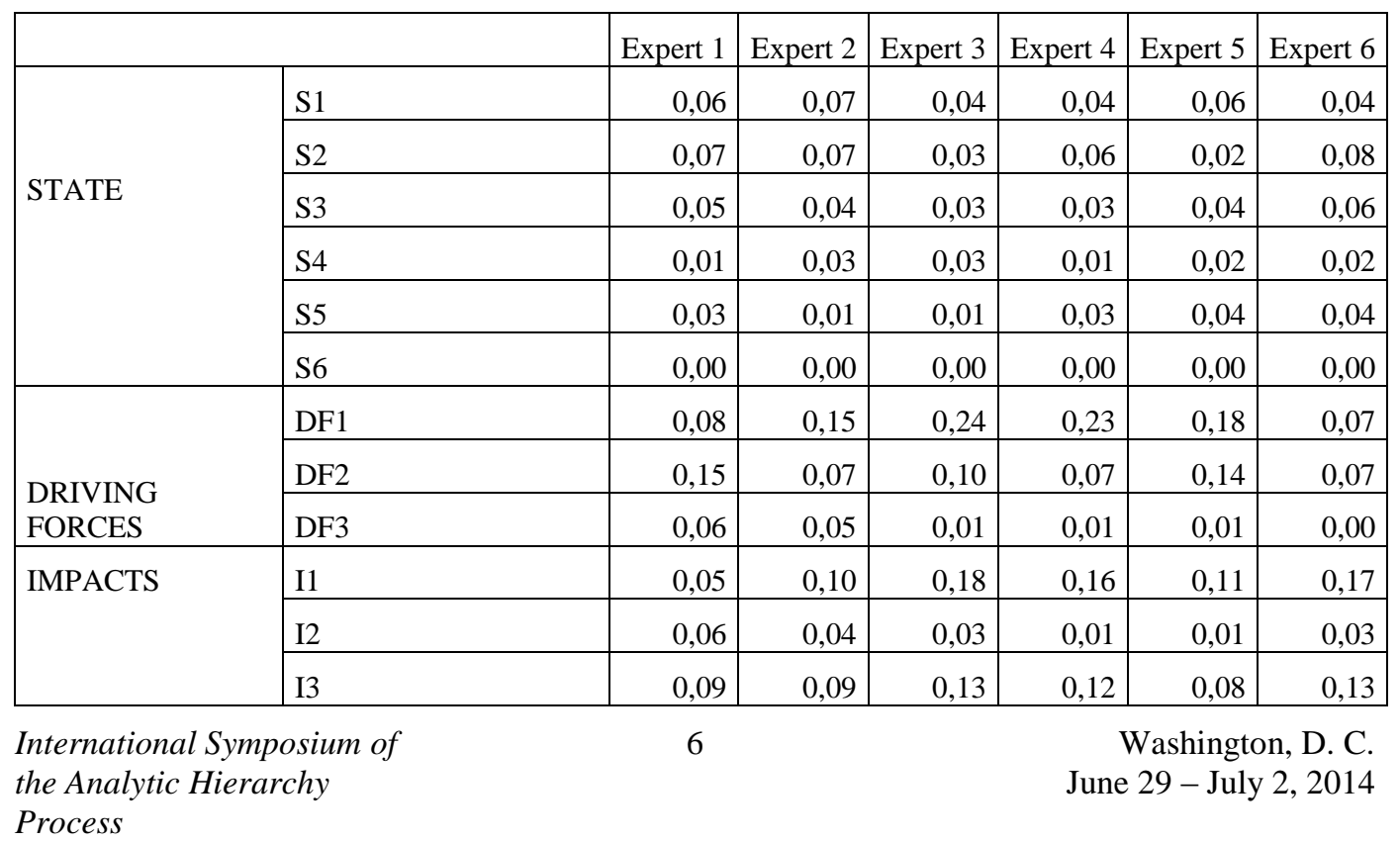


Modelling decision making in the management of national parks: Díaz-Martin et al. , International Symposium of the Analytic Hierarchy Process 2014, Washington D.C., U.S.A.

\begin{tabular}{|c|c|c|c|c|c|c|c|}
\hline & I4 & 0,05 & 0,03 & 0,01 & 0,01 & 0,03 & 0,01 \\
\hline & I5 & 0,10 & 0,06 & 0,03 & 0,05 & 0,04 & 0,05 \\
\hline \multirow{4}{*}{ PRESSURES } & $\mathrm{P} 1$ & 0,07 & 0,06 & 0,02 & 0,05 & 0,08 & 0,08 \\
\hline & $\mathrm{P} 2$ & 0,02 & 0,03 & 0,03 & 0,04 & 0,05 & 0,05 \\
\hline & $\mathrm{P} 3$ & 0,04 & 0,01 & 0,01 & 0,02 & 0,01 & 0,03 \\
\hline & $\mathrm{P} 4$ & 0,03 & 0,09 & 0,06 & 0,09 & 0,08 & 0,08 \\
\hline \multirow{7}{*}{$\begin{array}{l}\text { RESPONSES / } \\
\text { ALTERNATIVES }\end{array}$} & $\mathrm{R} 1$ & 0,55 & 0,49 & 0,40 & 0,36 & 0,52 & 0,46 \\
\hline & $\mathrm{R} 2$ & 0,15 & 0,05 & 0,10 & 0,12 & 0,07 & 0,09 \\
\hline & R3 & 0,04 & 0,28 & 0,30 & 0,36 & 0,29 & 0,12 \\
\hline & R4 & 0,16 & 0,06 & 0,03 & 0,02 & 0,06 & 0,14 \\
\hline & $\mathrm{R} 5$ & 0,08 & 0,08 & 0,15 & 0,10 & 0,05 & 0,14 \\
\hline & R6 & 0,00 & 0,00 & 0,00 & 0,00 & 0,00 & 0,00 \\
\hline & $\mathrm{R} 7$ & 0,03 & 0,04 & 0,02 & 0,03 & 0,01 & 0,04 \\
\hline
\end{tabular}

Table 1. Normalized limit supermatrix for PN Waraira Repano management

\section{Conclusions}

The findings confirm that stakeholders hold different interests, approaches to sustainability and sensitivities. After ANP all stakeholders understand better their interests and the others'. Thus, an improved participation is obtained and a consensus, or at least general agreements, is more likely. Also a better commitment to the overall objective is achieved as the decision model facilitates improving the alternatives design in order to lessen the possible burdens for specific stakeholders or the environment.

\section{Acknowledgments}

The research presented in this paper has been co-funded by the the Universitat Politècnica de València and the Decanato de Investigación y Desarrollo Académico of Universidad Metropolitana in Venezuela.

\section{Key References}

Atkins, J. D. Burdon, M. Elliot y A. Gregory (2011). Management of the marine environment: Integrating ecosystem services and societal benefits with the DPSIR framework in a systems approach. Marine Pollution Bulletin, Volume 62 (2): 215-226 Brown, R. y G. Harris (2005) Comanagement of wildlife corridors: the case for citizen participation in the Algonquin to Adirondack proposal Journal of Environmental Management, 74 (2): 97-106

Buta, N., S. Holland y K. Kaplanidou (2014). Local communities and protected areas: The mediating role of place attachment for pro-environmental civic engagement. Journal of Outdoor Recreation and Tourism, 5-6: 1-10

Daim, M. A. Bakri, H. Kamarudin, y S. Zakaria (2012). Being Neighbor to a National Park: Are We Ready for Community Participation? Procedia - Social and Behavioral Sciences, 36: 211-220

de Felipe, J. y B. Sureda (2009) Análisis Sistémico de Cataluña. II Congreso Internacional de Medida y Modelización de la Sostenibilidad, Barcelona. 22pp

International Symposium of 7

the Analytic Hierarchy

Washington, D. C. Process June 29 - July 2, 2014 
Modelling decision making in the management of national parks: Díaz-Martin et al. , International Symposium of the Analytic Hierarchy Process 2014, Washington D.C., U.S.A.

Diaz-Martin, D., Z. Martinez, E. Yerena, I. Novo, M. Febres, Y. Frontado y J. Trabucco. (2008). Semáforo de Parques Nacionales de Venezuela: Una herramienta para promover su apropiado manejo y conservación. En: VI Congreso de Investigación y Creación Intelectual de la Universidad Metropolitana. $247 \mathrm{pp}$.

Fancy, G., J. Gross y S. Carter (2009). Monitoring the condition of natural resources in US national parks. Environ Monit Assess, 151:161-174

García-Melón, M., T. Gómez-Navarro y S. Acuña-Dutra (2012) A combined ANP-delphi approach to evaluate sustainable tourism. Environmental Impact Assessment Review, 34: 41-50

Hämäläinen R., y T. Seppäläinen (1986). The analytic network process in energy policy planning. Socioeconomic Planning Sciences, 20(6): 399-405.

Mangi, S., Roberts, C. y Rodwell, L. (2007). Reef fisheries management in Kenya: Preliminary approach using the driver-pressure-state-impacts-response (DPSIR) scheme of indicators. Ocean \& Coastal Management, 50 (5-6): 463-480

Ness, B., S. Anderberg, y L. Olsson (2010). Structuring problems in sustainability science: The multi-level DPSIR framework Geoforum, Volume 41 (3): 479-488

ParksWatch, 2004

Saaty, T. (2005) Theory and applications of the Analytic Network Process: decision making with benefits, opportunities, costs and risks. RWS Publications: Pittsburgh; 2005. Sotelo, A., A. Tolón y X. Lastra (2011). Indicadores por y para el desarrollo sostenible, un estudio de caso. Estudios Geográficos, 72 (271).

Tallis, H., P. Levin, M. Ruckelshaus, S. Lester, K. McLeod, D. Fluharty y B. Halpern. (2010). The many faces of ecosystem-based management: Making the process work today in real places, Marine Policy, 34 (2): 340-348

Taring, H. (1992). Community Participation: The First Principle. IUCN Monographic Series. Karachi

Tscherning, K., K. Helming, B. Krippner, S. Sieber, y S. Gomez (2012) Does research applying the DPSIR framework support decision making? Land Use Policy, Volume 29: $1,102-110$ 